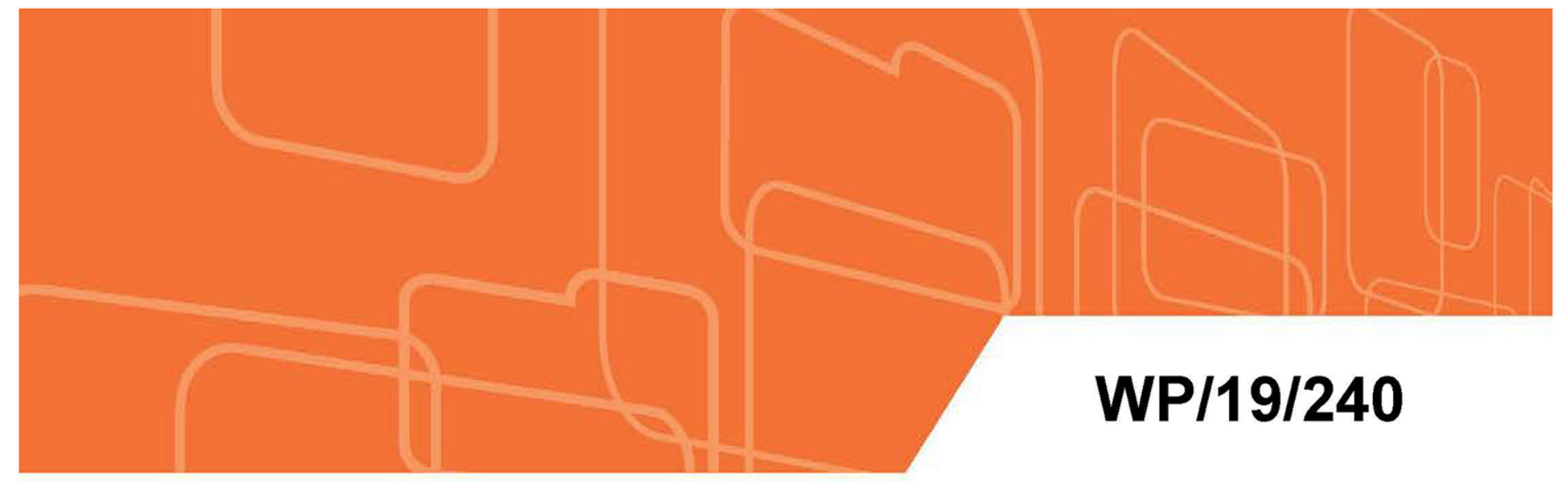

\title{
Pricing Sovereign Debt in Oil-Rich Economies
}

by Thomas McGregor

IMF Working Papers describe research in progress by the author(s) and are published to elicit comments and to encourage debate. The views expressed in IMF Working Papers are those of the author(s) and do not necessarily represent the views of the IMF, its Executive Board, or IMF management. 


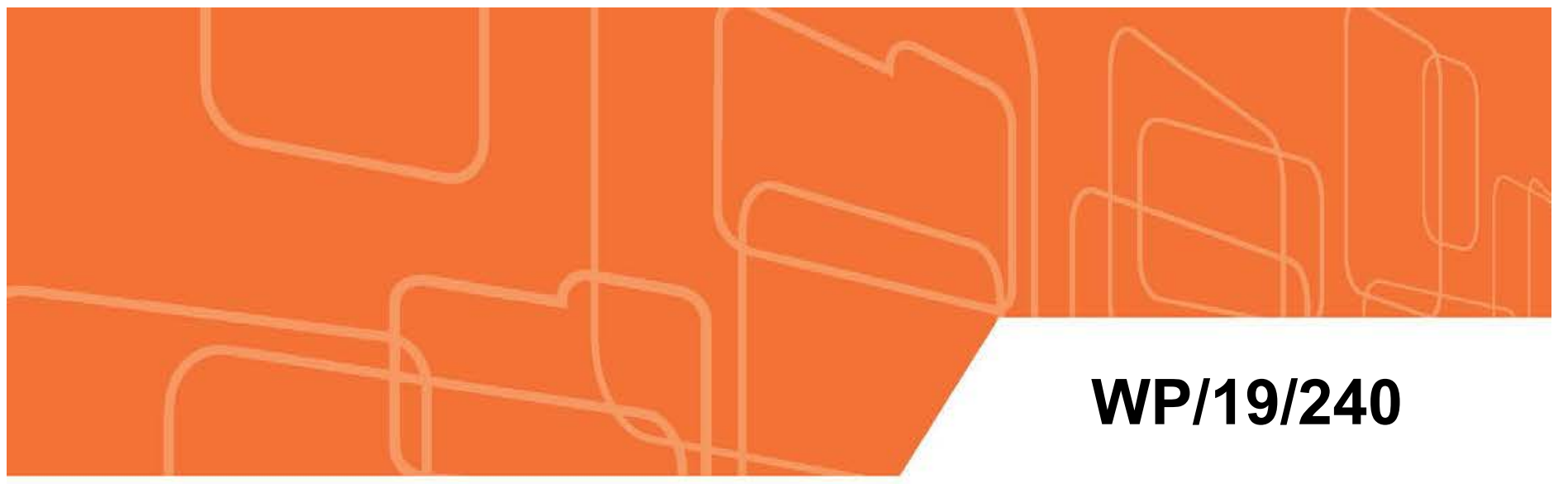

\section{IMF Working Paper}

\section{Pricing Sovereign Debt in Oil-Rich Economies}

by Thomas McGregor

IMF Working Papers describe research in progress by the author(s) and are published to elicit comments and to encourage debate. The views expressed in IMF Working Papers are those of the author(s) and do not necessarily represent the views of the IMF, its Executive Board, or IMF management.

$$
\text { I N T E R N A T I O N A L M O N E T A R Y F U N D }
$$




\title{
IMF Working Paper
}

\author{
African Department \\ Pricing Sovereign Debt in Resource-Rich Economies \\ Prepared by Thomas McGregor ${ }^{1}$
}

Authorized for distribution by Benedict Clements

November 2019

IMF Working Papers describe research in progress by the author(s) and are published to elicit comments and to encourage debate. The views expressed in IMF Working Papers are those of the author(s) and do not necessarily represent the views of the IMF, its Executive Board, or IMF management.

\begin{abstract}
How do oil price movements affect sovereign spreads in an oil-dependent economy? I develop a stochastic general equilibrium model of an economy exposed to co-moving oil price and output processes, with endogenous sovereign default risk. The model explains a large proportion of business cycle fluctuations in interest-rate spreads in oil-exporting emerging market economies, particularly the countercyclicallity of interest rate spreads and oil prices. Higher risk-aversion, more impatient governments, larger oil shares and a stronger correlation between domestic output and oil price shocks all lead to stronger comovements between risk premiums and the oil price.
\end{abstract}

JEL Classification Numbers: E32, E44, F34, G15, H63, O11

Keywords: Risk premium, natural resources, sovereign debt, and default, development Author's E-Mail Address: tmcgregor@imf.org

\footnotetext{
${ }^{1}$ I would like to thank Benedict Clements, Emre Alper, David Grigorian, Hippolyte Balima, Daniel Hardy, Ravi Balakrishnan, Monique Newiak, Carlo Pizzinelli, Paolo Dudine, Cristian Alonso, Olivier Basdevant, John Hooley, Mahvash Qureshi, Nelson Sobrinho, and the AFR RAG as well as participants of the AFR External Sector Issues Network for useful comments and suggestions on the paper. I would also like to thank Tony Venables, Rick van der Ploeg, Christopher Adam, Sam Wills, Brock Smith, Tim Willems, and members of the OxCarre Group at the University of Oxford for their comments. Any remaining errors are my own.
} 
II. EMERGING MARKET SOVEREIGN SPREADS ___________ $\underline{\mathbf{5}}$

III. THE MODEL ____________________________________________________________

IV. QUANTITATIVE ANALYSIS _____ $\frac{12}{12}$

A. Main calibration________ $\frac{12}{12}$

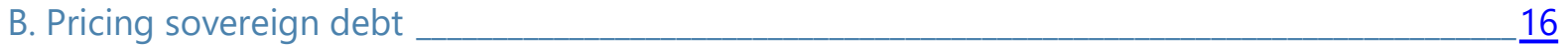

V. MODEL PERFORMANCE __________

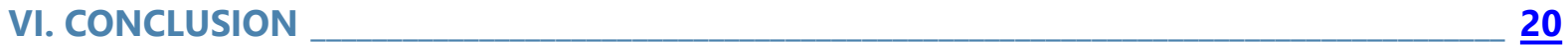

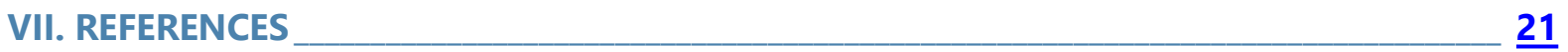

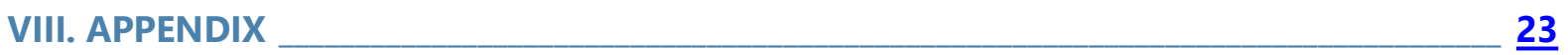

A. Ramsey representation_______ 23

B. Bivariate Markov shocks______ 24

C. Solving the model_______ $\frac{26}{27}$

D. Sensitivity ________

\section{FIGURES}

1a. Sovereign spreads and GDP
1b. Sovereign spreads and the oil price

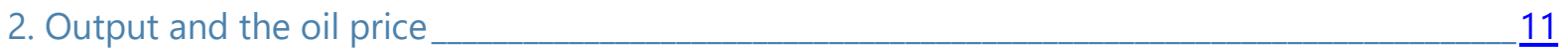

3. Bond pricing schedule______ $\frac{18}{28}$

A1. Dependence and impatience ______________________________________

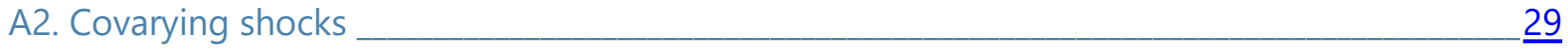

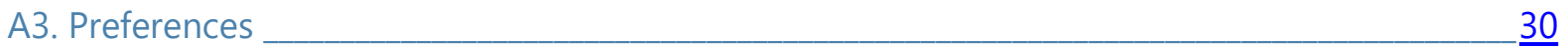

\section{TABLES}

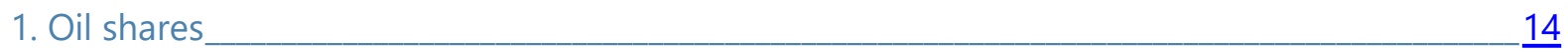

2. Calibration ___ $\frac{16}{19}$

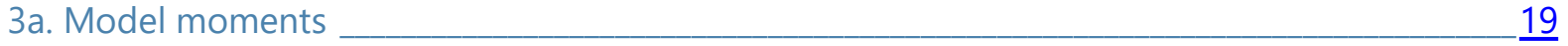

3b. Model correlations _____ $\frac{19}{28}$

A1a. Model moments___ $\frac{28}{28}$

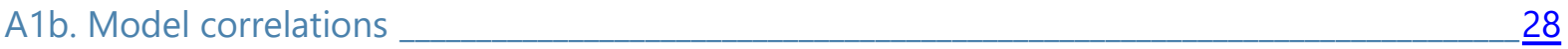




\section{INTRODUCTION}

After a series of high-profile sovereign defaults in the late-1990s and early-2000s, including by Russia, Ecuador and Argentina, the question of how to deal with default episodes and their economic impact moved to the forefront of international policy discussions. Interest was renewed by the debt crises that engulfed some eurozone countries following the financial crisis of 2007/08. The collapse in commodity prices in 2014/15 sparked a new wave of debt distress across the resource-dependent developing world leading to the de-facto default by Mozambique in early 2017. Today the IMF has warned that 40 percent of sub-Saharan Africa's low-income countries are now rated as being either in, or at high risk of, debt distress, while sovereign spreads remain low in the region's frontier economies ${ }^{2}$. With oil prices expected to remain well below their 2014 peak, and the sharp rise in sovereign debt levels in many developing and emerging market economies, the question of debt dynamics and the risk of default in these settings is as pertinent as ever.

This paper investigates how oil price movements affect sovereign spreads in an oil-dependent emerging market economy, and what this means for market access and pricing of sovereign debt in these settings. I develop a stochastic general equilibrium model of an oil-dependent economy with sovereign debt and endogenous default. The model consists of a small open economy that receives a stochastic stream of income from production as well as from resource export revenues, which co-vary. The government chooses the level of consumption in every period that maximizes a representative agent's utility subject to the resource constraint and has access to international financial markets where it can buy one-period bonds. It also chooses whether to default on existing debt or not, where defaulting carries some cost. International investors form expectations on the likelihood of default in any given period and charge a premium on sovereign borrowing to account for this credit risk.

The model can explain a large proportion of business cycle fluctuations in interest-rate spreads in oil-dependent, emerging market economies, particularly the countercyclical movements of interest rate spreads with oil prices. One conclusion for policy makers is that it may be it optimal to smooth the volatility risks associated with oil price shocks by building up liquid buffers and/or pay down debt. This could help insulate the economy from commodity-driven movements in risk premiums and reduce 'stop-go' cycles of investment and growth.

There is a growing empirical literature investigating the relationship between sovereign default, interest rate spreads, and local economic conditions in emerging economies. Volatile interest rate spreads have been found to be an important driver of output volatility in developing and emerging market economies (Neumeyer and Perri, 2005; Uribe and Yue, 2006; Aguiar and Gopinath, 2006). For commodity exporters, higher commodity prices can have positive short-term effects on output and growth but adverse long-term effects (see Deaton et al., 1995; Raddatz, 2007; McGregor, 2017). This is particularly true in countries with poor governance (Collier and Goderis, 2012; Mehlum et al., 2006). ${ }^{3}$ Recent work by

\footnotetext{
${ }^{2}$ IMF (2018) Regional Economic Outlook, Spring 2018, sub-Saharan Africa.

${ }^{3}$ An extensive literature on the 'resource curse' (Sachs and Warner, 1999) examines the plethora of mechanisms through which natural resources can be either a 'curse' or a 'blessing' (van der Ploeg. 2011).
} 
Restrepo-Echavarria et al. (2016) focusing on oil producing economies, documents a strong negative correlation between risk premiums and oil prices. Finally, empirical work by the IMF (2017) points to large variation in the drivers of spreads.

This paper is most closely related to the seminal work of Eaton and Gersovitz (1981) and Grossman and Van Huyck (1988) on optimal default ${ }^{4}$. Arellano (2008) develops a small open economy model of default under limited commitment. The model delivers a strongly countercyclical process for interest rate spreads and output. Default is more likely in recessions because this is when it is most costly for a risk averse borrower to repay noncontingent debt. Lopez-Martin et al. (2016) develop a DSGE model of sovereign default to study fiscal policy in commodity exporting economies and argue for the use of financial hedging instruments to reduce volatility in fiscal adjustment. Adam and Grill (2017) extend the existing Ramsey policy literature to a setting with non-contingent sovereign debt and continuous default costs. They find that, when government bond markets are incomplete, partial default can be Ramsey optimal when a country's wealth is sufficiently low. ${ }^{5}$

Whilst some recent work investigates the empirical nature of this question (Arezki and Bruckner, 2012), to the best of my knowledge, this paper is the first to address these questions using a structural macroeconomic model. The paper investigates the link between oil prices, business cycle dynamics, and risk premiums in oil-dependent, emerging markets. Whilst causality is always difficult to ascertain, the focus here is to highlight the mechanism through which oil price movements may affect sovereign yields, namely optimal default likelihood. The use of a structural model allows us to derive and analytic expression for the relationship between oil prices and sovereign spreads and to provide insights for policy.

The paper is organized as follows. Section II describes the evolution of interest rate spreads in resource-rich, emerging market economies and presents some evidence for a countercyclical relationship between spreads and oil prices. Section III sets out the stochastic debt model and section IV describes the main calibration and results of a baseline model simulation. Section V assesses the model's performance and Section VII concludes.

\section{EMERging Market Sovereign SpREAdS}

There is growing evidence that emerging market output volatility may be related to the ability for emerging markets to access international financial markets in times of need. In particular, a large part of the volatility in output has been shown to be due to highly countercyclical interest rates and countercyclical default risk. Work by Neumeyer and Perri

\footnotetext{
${ }^{4}$ The former develops a model of sovereign debt in which the possibility of permanent market exclusion following default generates an endogenous debt limit; below which it is always optimal to service outstanding debt, but above which default is optimal for the sovereign. The latter show that even non-permanent market exclusion can present a sufficient risk to the sovereign, yielding a similar result (see also Kletzer \& Wright, 2000). Finally, Park (2017) shows that in a model with capital accumulation default can also occur in 'good' times. The model delivers a U-shape in the capital stock: at both low and high levels of capital, the economy has an incentive to default on its debt. Default in good times occurs when the economy has over-invested in capital during booms.

${ }^{5}$ Others include the inclusion of long-term debt (Chatterjee \& Eyigungor, 2012), CRRA lenders (Lizaro, 2017), misspecified default probabilities (Pouzo \& Presno, 2016) and bailout risk (Fink \& Scholl, 2016).
} 
(2005) present evidence that in contrast to developed economies, emerging market business cycles are more volatile and interest rates are countercyclical and lead the economic cycle. Uribe and Yue (2006) show that most of the movements in emerging market spreads are due directly to changes in the country specific spread, or the risk-premium. To date, the literature has remained relatively silent on these issues in a resource-rich setting. The obvious question then is: how important are oil price movements in driving the business cycle in these settings?

Figure 1a below plots quarterly real GDP in logs and the 10-year USD denominated government bond yield over the US for six resource-rich economies: Angola, Colombia, Indonesia, Mexico, Nigeria and Russia ${ }^{6}$ and covers the period 1995q1-2016q $3^{7}$. Interest rate spreads in these economies have been volatile, as have GDP growth rates. The various economic downturns are visible for each country, with an upward spike in the interest rate spread coinciding with, and often leading, the economic slump. All experienced sharp downturns between 2009 and 2010 in the aftermath of the financial crisis, apart from Indonesia which recovered relatively quickly.

Critically, these countries are highly resource-dependent and rely heavily on oil exports as a source of foreign exchange. An empirical regularity in these economies is a negative correlation between oil prices and interest rate spreads (Restrepo-Echavarria et al., 2016). Spreads remain low during the 'good' times when oil prices are high and rise in the 'bad' times. This negative relationship is clearly visible in Figure 1b, which plots the real-world oil price against the interest rate spreads for these six economies. The price of crude oil has been highly volatile, with a pronounced boom and bust cycle during the 2007/08 financial crisis and a continued downward spiral since the end of 2014. It has fluctuated between a low of around \$US 25 in 2001q4 and a peak of \$US 124 in 2008q2. Spreads have also been volatile and negatively correlated with the oil price. This negative relationship between the mean interest rate spread and the oil price is confirmed with a correlation coefficient of -0.36 , which is statistically significant at better than the 1 percent confidence level. ${ }^{8}$ For non-oil exporting countries the correlation is not statistically different from zero. Global factors, such as global liquidity and risk appetite may drive movements in both the oil price and sovereign spreads. Controlling for the VIX in a simple regression of spreads on oil prices does not change the resulting negative correlation for these economies.

\footnotetext{
${ }^{6}$ These six countries comprise the full set of oil-dependent emerging market economies for which we have quarterly GDP and interest-rate data and have outstanding USD denominated bonds.

${ }^{7}$ The interest rate spread is the difference between the yield on 10-year USD denominated government bonds in each emerging economy and that of the US. The use of USD denominated bonds over local currency bonds strips out FX risk spreads that may eb country specific and focuses solely on credit risk, the object of interest. ${ }^{8}$ The individual country correlations are: Angola $=-0.6$, Colombia $=-0.63$, Indonesia $=-0.03$, Mexico $=-0.09$, Nigeria $=-0.28$, and Russia $=-0.56$.
} 


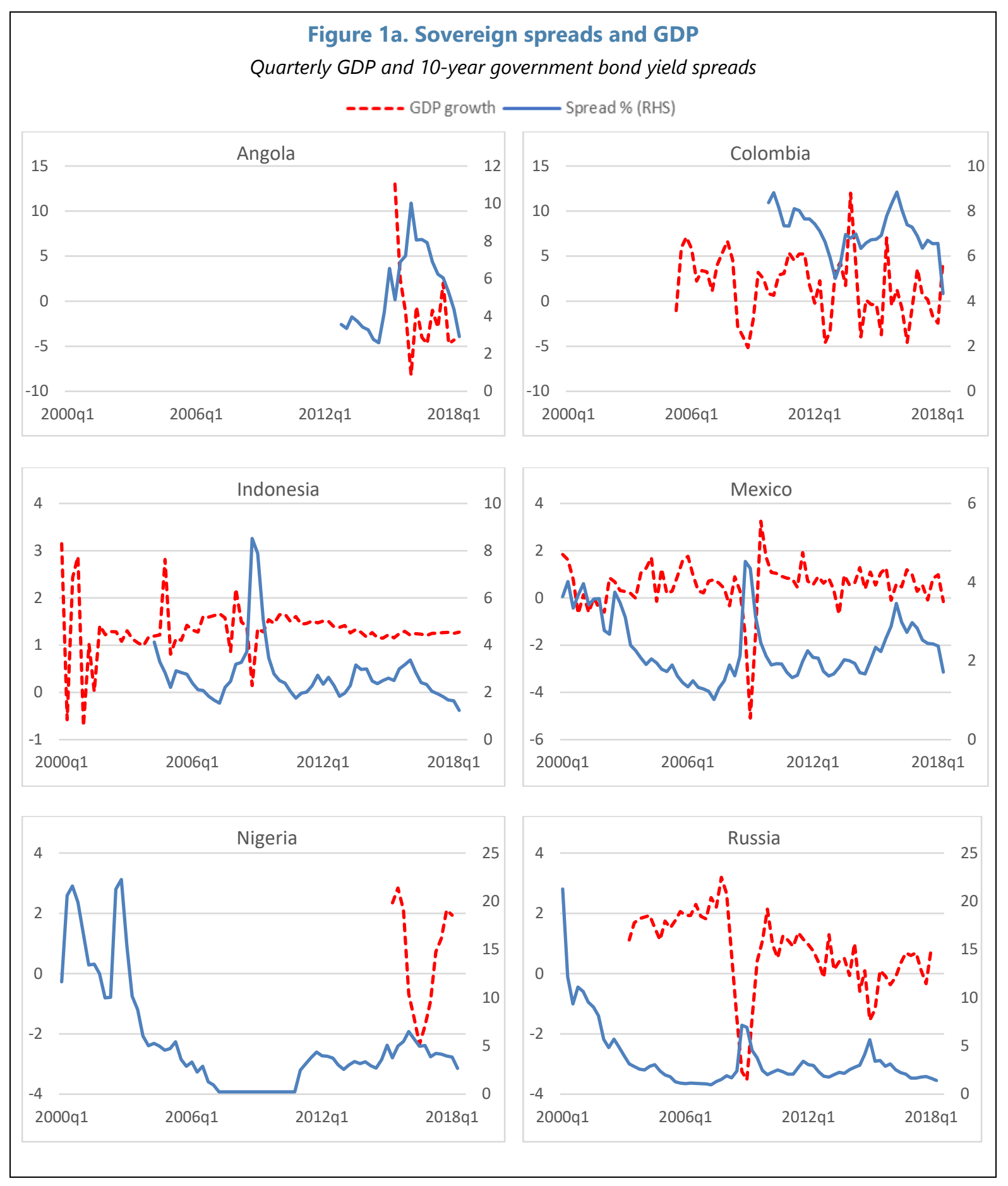

CInternational Monetary Fund. Not for Redistribution 


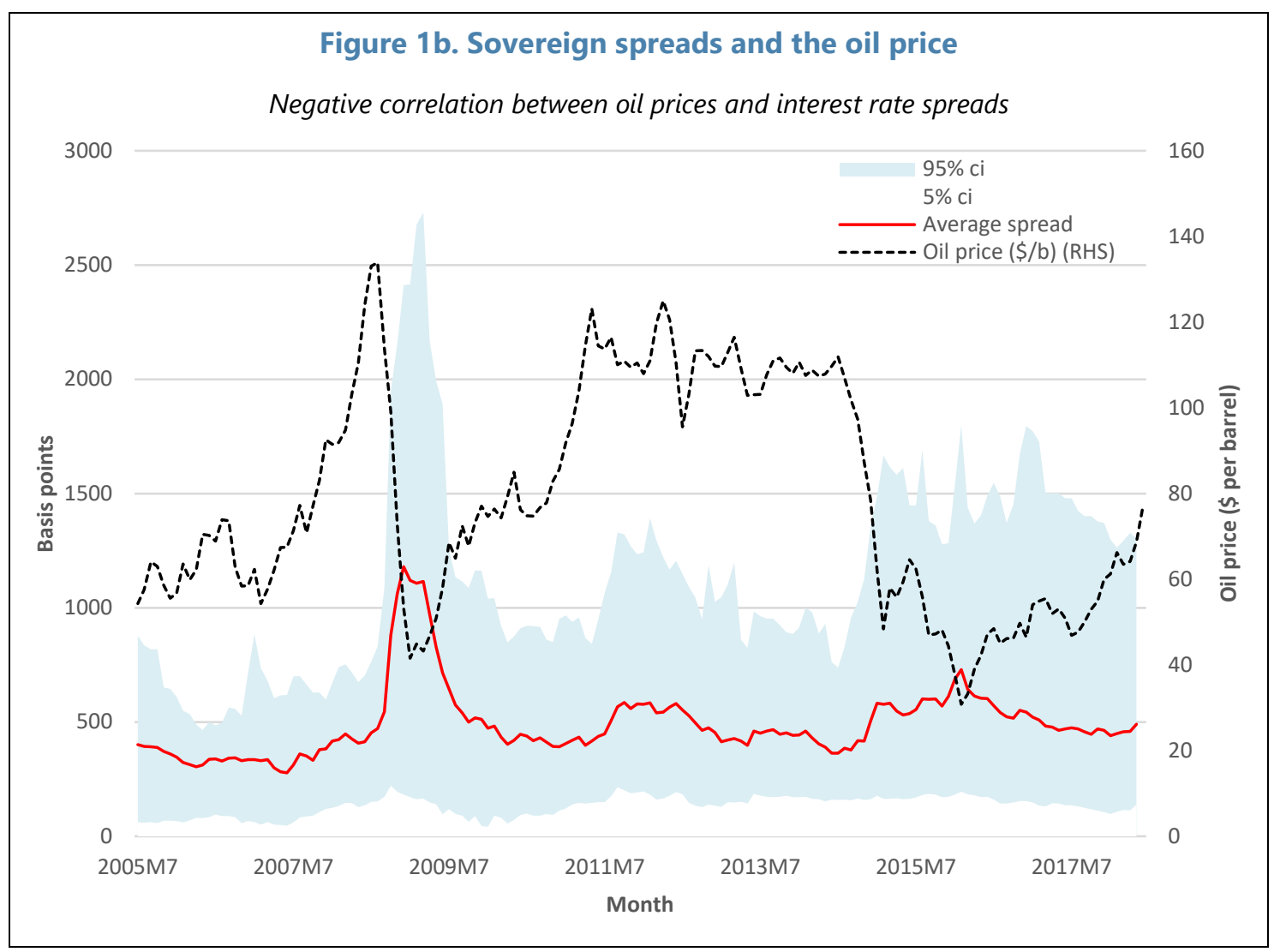

III. THE MODEL

The model structure is based on work by Eaton and Gersovitz (1981) on international lending which has been extended by Arellano (2008) to study the default experience of Argentina. Recent work by Lopez-Martin et al. (2016) takes a similar approach to the sovereign's problem, focusing on the implications for fiscal policy. Consider a government that seeks to maximize the utility, $u_{t}=f\left(c_{t}\right)$, of a representative, who receives two stochastic streams of income; one from output, $y$, and one from tax revenues from the oil sector, which are driven by a volatile oil price, $p$, as follows:

$$
\begin{aligned}
& y_{t}=\mu_{y}+z_{t} \\
& z_{t}=\rho_{z} z_{t-1}+\varepsilon_{t}^{z} \\
& \varepsilon_{t}^{z} \sim N\left(0, \sigma_{z}^{2}\right) \\
& p_{t}=\mu_{p}+z h_{t} \\
& h_{t}=\rho_{h} h_{t-1}+\varepsilon_{t}^{h} \\
& \varepsilon_{t}^{h} \sim N\left(0, \sigma_{h}^{2}\right)
\end{aligned}
$$

where $\mu_{y}$ and $\mu_{p}$ are the means of output and the oil price respectively, and $\varepsilon_{t}^{Z}$ and $\varepsilon_{t}^{h}$ are the i.i.d shocks to each series. 
Given the observed shocks, the government chooses the level of consumption today and makes a default decision. The government chooses either to default on existing debt, $D$, or to not default and continue servicing the debt stock, $N$. The resource constraint faced by the government will depend on the default choice. Should the government choose not to default, it then has access to international financial markets where it can buy one-period bonds.

In the default state consumption is simply equal to income plus oil revenues under default, $c^{D}=y^{D}+o^{D}$, where $y^{D}$ and $o^{D}$ are defined as follows:

$$
\begin{aligned}
& y_{t}^{D}=\left\{\begin{array}{cc}
y_{t} & \text { if } y_{t}<\bar{y} \\
\hat{y}=\psi \bar{y} & \text { if } y_{t}>\bar{y}
\end{array}\right. \\
& o_{t}^{D}=\left\{\begin{array}{cc}
p_{t} \bar{s} & \text { if } p_{t}<\bar{p} \\
\hat{o}=\psi(\bar{p} \bar{s}) & \text { if } p_{t}>\bar{p}
\end{array}\right.
\end{aligned}
$$

where $\psi \in(0,1)$ represents the (common) output and oil revenue cost of default (higher $\psi$ means lower cost of default), $\bar{y}=\mathrm{E}\{y\}$ is expected output and $\bar{p}=\mathrm{E}\{p\}$ the expected oil price, $\bar{s}$ is the annual flow of extracted oil, assumed to be fixed. The default cost is assumed to be a fixed proportion of income for sufficiently high levels of income.

If the government defaults it is then assumed to be in autarky (i.e. the country is excluded from capital markets) with an exogenous probability of re-entry in the future. If either output or the oil price is above their respective means, then actual output and oil revenues under default is truncated down by a fixed proportion of the expected variables, as governed by the cost parameter, $\psi$. The result is an asymmetric cost of default schedule. The output and oil revenue processes are truncated because it is assumed that default entails some direct cost. For output these costs may arise due to the inability of firms to access credit for investment or imports, reduced foreign investment, costly legal processes, political upheaval and civil protest, etc. For oil revenues, defaulting may simply result in a punitive default procedure in which the taxation of oil revenue, which is an immediate source of foreign exchange earnings for the government, are used to pay preferred creditors immediately. ${ }^{9}$ The main motivation for doing this is to bring the default probability implied by the model in line with the data (see Arellano, 2008).

In the no-default state consumption, $c^{N}$, is equal to stochastic income plus oil revenue plus new borrowing, net of interest payment on existing borrowing as follows:

$$
c_{t}^{N}=y_{t}+p_{t} \bar{s}-q_{t}\left(d_{t+1}, y_{t}, p_{t}\right) d_{t+1}+d_{t}
$$

where, $d_{t+1}$ represents one-period bonds sold at price $q_{t}$, and $d_{t}$ is the repayment due to previous borrowing (for indebted countries, $d<0$ ). Every period the sovereign's maximization decision can be expressed in value function form as follows:

\footnotetext{
${ }^{9}$ The output process is truncated if the sovereign chooses to default in any period. This truncation imposes a ceiling on output. A similar process applies to oil revenues under default.
} 


$$
V\left(d_{t}, y_{t}, p_{t}\right)=\max _{D, N}\left\{V^{D}\left(y_{t}, p_{t}\right), V^{N}\left(d_{t}, y_{t}, p_{t}\right)\right\}
$$

where output, $y_{t}$ follows the stochastic process defined above, and $d_{t}$ denotes the asset stock of the sovereign $\left(d_{t}<0\right.$ signifies indebtedness). The expression in (6) highlights nested feature of the model that is due to the non-linearity from optimal default. Essentially, the sovereign must solve for optimal consumption under different states of the world (shocks), for both default and non-default, before constructing its overall value function. Default is chosen by the sovereign if $V^{D}>V^{N}$.

We now move to defining utility. How agents make inter-temporal trade-offs and how they treat risk are likely to be important in any analysis of sovereign debt dynamics in a stochastic setting. A substantial literature exists documenting the low degree of inter-temporal substitution in developing and emerging market economies, as well as the relatively high risk-aversion, although the evidence here is more mixed. I assume utility takes CRRA form using Epstein-Zin preferences as defined by Caldara et al. (2012), in which the risk-aversion and substitution parameters are independent from each other. ${ }^{10}$ The present value for the sovereign under default, $V^{D}$, is therefore given by:

$$
V^{D}\left(y_{t}, p_{t}\right)=\left[u\left(y_{t}^{D}+o_{t}^{D}\right)^{\frac{1-\sigma}{\eta}}+\beta \mathrm{E}_{t}\left[\theta V\left(0, y_{t+1}, p_{t+1}\right)+(1-\theta) V^{D}\left(y_{t+1}, p_{t+1}\right)\right]^{\frac{1-\sigma}{\eta}}\right]^{\frac{\eta}{1-\sigma}}
$$

whilst the present value under non-default, $V^{N}$, is given by:

$$
V^{N}\left(d_{t}, y_{t}, p_{t}\right)=\max _{d_{t+1}}\left[u\left(c_{t}^{N}\right)^{\frac{1-\sigma}{\eta}}+\beta \mathrm{E}_{t}\left[V\left(d_{t+1}, y_{t+1}, p_{t+1}\right)\right]^{\frac{1-\sigma}{\eta}}\right]^{\frac{\eta}{1-\sigma}}
$$

where $\theta$ is an exogenously determined probability of re-entry into credit markets after default, $\sigma \geq 0$ is the coefficient of relative risk aversion, $\xi \geq 0$ is the inter-temporal elasticity of substitution (IES), $\mathrm{E}$ is the expectations operator, and $\eta=(1-\sigma) /(1-(1 / \xi))$. Under deterministic preferences, we would set the IES equal to the inverse of the risk aversion parameter, i.e. $\sigma=1 / \xi$ and $\eta=1$, so the recursive preferences collapse to the standard time-separable expected CES discounted utility with discount factor $\beta$.

Following the approach taken by Binsbergen et al. (2008) and Stähler (2011), we can express the expected future value, depending on whether the government chooses to default or not, as a continuation value of the government's optimization problem. These are given by:

$$
E_{t} V^{D}\left(y_{t+1}, p_{t+1}\right)=\sum_{y=1}^{y n} \sum_{p=1}^{p n}\left[\theta V\left(0, y_{t+1}, p_{t+1}\right)+(1-\theta) V^{D}\left(y_{t+1}, p_{t+1}\right)\right] \Pi\left(y_{t+1}, p_{t+1} \mid y_{t}, p_{t}\right)
$$

under default, and:

\footnotetext{
${ }^{10}$ Another option would be to use some form of hyperbolic preferences following work by Laibson (1997).
} 


$$
E_{t} V^{N}\left(d_{t+1}, y_{t+1}, p_{t+1}\right)=\sum_{y=1}^{y n} \sum_{p=1}^{p n}\left[V\left(d_{t+1}, y_{t+1}, p_{t+1}\right)\right] \Pi\left(y_{t+1}, p_{t+1} \mid y_{t}, p_{t}\right)
$$

under no-default. We define a transition probability matrix, $\Pi$, for the shock processes following Tauchen (1986), which allows the oil price and output processes to covary ${ }^{11}$. The transition matrix is given by:

$$
\Pi\left(y_{t+1}, p_{t+1} \mid y_{t}, p_{t}\right)=\operatorname{Pr}\left(y_{t+1}, p_{t+1} \mid y_{t}, p_{t}\right)
$$

It seems plausible that for resource rich economies, positive terms-of-trade shocks (that is, increases in the price of oil relative to imports) might lead to increases in domestic output. In the model, output, $y$, is defined as total non-oil output while the resource sector is defined as, $o=p \bar{s}$, where the oil price, $p$ is subject to shocks. So positive co-movements in this setting would be between oil prices and non-oil output.

This co-movement can be seen in figure 2 below which plots the oil price against the cyclical component of GDP in the six economies. The mean correlation coefficient between real GDP and the oil price in our six economies is $0.2^{12}$.

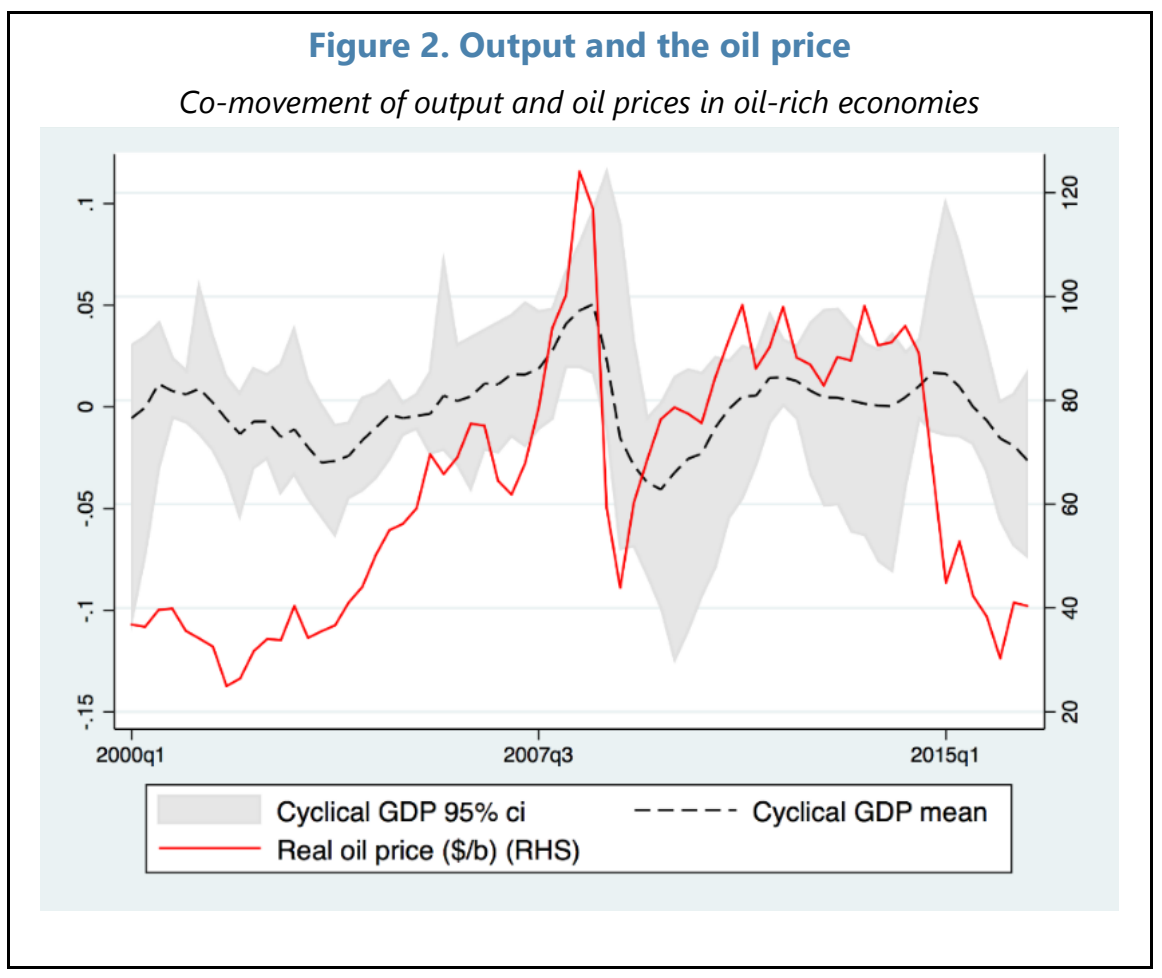

The co-movement of output and oil prices could be driven by several factors. On the production side the economy produces may be capable of switching only imperfectly between domestic non-tradables and exports. There may also be upstream and downstream

\footnotetext{
11 The derivation of the transition matrix is described more fully in section B of the appendix.

12 The individual country correlations are: Angola $=0.76$, Colombia $=0.41$, Indonesia $=-0.06, \mathrm{Mexico}=0.14$, Nigeria $=0.26$, and Russia $=0.29$.
} 
linkages between the oil sector and the non-oil sector as in Ferrero and Seneca (2015). Higher oil prices may also lead to increased financial inflows which boost non-oil growth.

Finally, creditors are assumed to be risk-neutral. They lend to the sovereign in the current period by buying bonds, $d_{t+1}$, at price $q_{t}$. In the following period, the creditors receive the face value of the bond if the sovereign does not default, and nothing if the sovereign defaults. The probability of default is given by:

$$
\delta\left(d_{t+1}, y_{t}, p_{t}\right)=\operatorname{Pr}\left[V^{D}\left(y_{t+1}, p_{t+1}\right)>V^{N}\left(d_{t+1}, y_{t}, p_{t}\right)\right]
$$

and the probability of the creditor getting paid (i.e. no default) is $1-\delta$.

The equilibrium condition from the above maximization problem of the sovereign, given financial markets risk preferences, is a bond pricing schedule, $q_{t}\left(d_{t+1}, y_{t}, p_{t}\right)$, as follows:

$$
q_{t}\left(d_{t+1}, y_{t}, p_{t}\right)=\frac{1-\mathrm{E}_{t}\left\{\delta\left(d_{t+1}, y_{t}, p_{t}\right)\right\}}{1+r_{t}}
$$

where $r_{t}$ is the risk-free interest rate. The bond price depends negatively on the default probability, $\delta\left(d_{t+1}, y_{t}, p_{t}\right)$, and the risk-free interest rate, $r_{t}$. A higher default probability reduced the price investors are willing to pay to hold the bond. A higher output realization, $y_{t}$ or lower debt position in the following period, $d_{t+1}$, feeds through to lower probability of default and so a higher bond price.

\section{Quantitative Analysis}

\section{A. Main calibration}

This section aims to present a sensibly parameterized model for the six resource-rich countries in our sample. I calibrate the model to reflect moderate risk-aversion and impatience, high oil dependence, and a positive correlation between domestic output and oil price shocks. The parameters are chosen to best fit key moments in the data, while remaining broadly within the bounds suggested in the literature. A sensitivity analysis on the key parameters is presented in Appendix D.

Due to the non-linear nature of the model, it is necessary to use numerical methods to solve for the optimal policy functions. This process is explained in more detail in the section $\mathrm{C}$ of the appendix. In addition to the baseline calibration, I investigate impact on the results of varying some of the key performance in the model, namely: oil dependence and impatience, co-movement of shocks, and preference structure. The details are presented in section D of the appendix.

\section{Inter-temporal substitutability}

Households in developing and emerging market economies are likely to have lower intertemporal elasticity of substitution (IES) for several reasons. The existence of subsistence consumption may result in an IES that is wealth dependent. At low income levels this implies 
a lower inter-temporal elasticity of substitution, and a savings rate that responds less to returns on capital (see Ravn et al., 2008). As wealth increases, the inter-temporal substitution of elasticity converges to that under standard CES preferences. At the aggregate level, in poor countries where budget shares of food are relatively high, the interest elasticity of saving is likely to be low, thus leading to a low inter-temporal elasticity (see Ogaki et al. (1996) for a discussion of these hypotheses). I set the IES parameter to $\xi=0.5$, which is consistent with the literature.

\section{Risk aversion}

On risk-aversion, the evidence in developing and emerging market settings is informative but far from conclusive. Several studies find that agents in developing countries are highly risk averse (Binswanger et al., 1980; Yesuf and Bluffstone, 2009; Akay et al., 2012). More recent work however, has argued that these earlier studies may be biased towards overestimating risk-aversion. Gandelman and Hernandez-Murillo (2014), for example, estimate a coefficient of relative risk aversion close to unity in developing countries, although risk aversion in African economies may be higher than in Asia. I set the risk-aversion parameter to $\sigma=70$, which is high, but consistent with the range used in the literature. The sensitivity of the model to this parameter choice is discussed in section D of the appendix.

\section{Impatience}

The permanent income theory of consumption yields the basic inter-temporal approach to the current account: in a small open economy, under perfect consumption smoothing, temporary income shocks will be offset by changes in national savings via the current account (Obstfeld and Rogoff, 1995; Sachs, 1982). This standard assumption of pure consumption smoothing is unlikely to hold in emerging markets where current generations discount the future more heavily due to stronger growth and greater uncertainty.

Consumption tilting, which arises due to differences between the subjective discount rate of the domestic agent and the prevailing world interest rate, yields behavior in which a country shifts its consumption toward the present or the future, independently of the balance of prevailing shocks to income. In general, agents in developed economies are observed to be relatively patient. ${ }^{13}$

Recent work has examined the degree of impatience in consumption in developing and emerging market settings. Zhuang et al. (2007) and Harrison (201) for example, find social discount rates that are significantly above prevailing market interest rates in poor countries. These high social discount rates are applied in practice by development organizations, such as the World Bank and the Asian Development Bank, who typically use annual discount rates in the range of $10-12 \%$ when evaluating projects in developing countries. Some developing country governments apply discount rates as high as $15 \%$ in their project appraisals.

\footnotetext{
${ }^{13}$ Braeu (2010) finds that households in Canada tilt consumption toward the future, while Cashin \& McDermott (2002) find that the dynamics of international capital flows to Australia during the 1990s, when the country was a net capital importer, were broadly consistent with utility maximisation under consumption smoothing.
} 
In addition, there is growing evidence of tax tilting in emerging markets, in which governments chooses fiscal deficits that are either larger or smaller than those generated from the trade-off between tax smoothing and debt-sustainability objectives. This suggests that even governments may display non-smoothing behavior. Cashin et al. (2003) find that taxes in Pakistan remained unresponsive to anticipated changes in expenditure, but that deficits were systematically larger over the 1970-90 period than would be expected from a series of optimal tax smoothing fiscal decisions. Tax tilting in may also be due to increased political risk. Pasten and Cover (2015) study the case of Latin America between 1984 and 2009 and find that a higher risk of losing power in the future increases the rate at which a government discounts the future resulting in higher deficits today.

The impatience parameter that is consistent with consumption smoothing, given a real interest rate of $2 \%{ }^{14}$ in our six economies, would be $\rho=0.02$. To account for the higher degree of impatience in emerging market economies I set $\rho=0.025$.

\section{Oil dependence}

How dependent the domestic economy is on oil revenues is a key parameter in the model. Given the model set-up, oil revenues are important as they provide vital foreign exchange earnings which can then be used to pay down foreign denominated debt. One way to calibrate this parameter would be to estimate the share of oil production in GDP. Using data from the World Bank's WDI database, I find the average share of oil and gas rents in total GDP across our sample of countries over the period $1995 \mathrm{q} 1$ to $2016 \mathrm{q} 4$ to be $6 \%$ Another way to calibrate this parameter would be to estimate the share of total export earnings which are due to oil exports. Using UN Comtrade data, I find the average share of petroleum in total exports to be $35 \%$.

Table 1 below gives these share estimates for each country. What is clear from the data is the large variation in oil shares (GDP or exports) across the six countries. ${ }^{15}$ I set the oil dependence parameter conservatively at $\bar{s}=0.132$.

\begin{tabular}{|ccc|}
\hline \multicolumn{3}{|c|}{ Table 1. Oil shares (\%) } \\
\hline Country & GDP share & Export share \\
\hline Angola & 39.9 & 59.5 \\
Colombia & 4.1 & 24.5 \\
Indonesia & 2.9 & 9.7 \\
Mexico & 3.7 & 13.0 \\
Nigeria & 18.6 & 57.3 \\
Russia & 10.1 & 32.2 \\
\hline All & 13.2 & 32.7 \\
\hline
\end{tabular}

\footnotetext{
${ }^{14}$ Calculated based on data between $1995 \mathrm{q} 1$ and 2016q4. The risk-free rate set equal to the US government 10year bond yield of $0.4 \%$ and an exogenous risk premium for emerging market 10 -year bonds of $1.6 \%$.

${ }^{15}$ It is worth noting that while the mean GDP share has remained relatively stable over time, the export share has increased steadily.
} 


\section{Covarying shocks}

The model includes two stochastic processes: innovations to output and the oil price. I calibrate the output series using quarterly data from the six economies and the oil price series using quarterly data on the real crude oil price over the period 1995q1 - 2016q3. ${ }^{16}$ I deflate the nominal GDP series for each country in local currency using the national GDP deflator, and the crude oil price using US CPI data, then remove the share of oil rents in GDP to obtain a measure of non-oil GDP ${ }^{17}$. I then take the natural $\log$ of these real GDP series and the real oil price. All data are quarterly. Finally, I pass the data through a Hodrick-Prescott (HP) filter with a smoothing parameter of $1600^{18}$.

To retrieve the structural parameters required for the model, I estimate a simple 2-variable VAR model for each country as follows:

$$
\begin{aligned}
& {\left[\begin{array}{l}
y_{t} \\
p_{t}
\end{array}\right]=\left[\begin{array}{l}
\mu^{y} \\
\mu^{p}
\end{array}\right]+\left[\begin{array}{cc}
\rho^{y} & \rho^{y p} \\
\ldots & \rho^{p}
\end{array}\right]\left[\begin{array}{c}
y_{t-1} \\
p_{t-1}
\end{array}\right]+\left[\begin{array}{c}
\varepsilon_{t}^{y} \\
\varepsilon_{t}^{p}
\end{array}\right]} \\
& {\left[\varepsilon^{y}, \varepsilon^{p}\right]^{\prime} \sim N\left(0, \Sigma_{y p}\right) \text { and } \Sigma_{y p}=\operatorname{Var}\left(\varepsilon^{y}, \varepsilon^{p}\right)=\left[\begin{array}{cc}
\sigma_{y}^{2} & \ldots \\
0 & \sigma_{p}^{2}
\end{array}\right]}
\end{aligned}
$$

where $y_{t}$ and $p_{t}$ are the cyclical component of the output and oil price series respectively at time $t$ and $\varepsilon_{t}^{i}$ are assumed to be an i.i.d errors. The coefficient estimates for $\rho^{j}$ are used to calibrate the autoregressive coefficients in the model, while the sample standard errors of the residuals are used to calibrate the volatility parameters.

As discussed in the previous section, there is a strong co-movement in the oil price and output processes in the six economies studied. Estimating equation (15) for each country separately yields a mean cross correlation between output and the oil price across each of the six economies in the sample of $\rho^{y p}=0.05$. In addition, the quarterly output process has a persistence term of 0.841 and is subject to an i.i.d shocks process with standard deviation of 0.015 , while the oil price has a persistence term of 0.725 and shock standard deviation of $0.136 .{ }^{19}$.

\section{Other parameters}

The probability of re-entry following default is set to $\theta=0.25$ every quarter. Using a monte carlo simulation approach, I find that, over 1000 runs, the average number of years that a country would be excluded from financial markets using this re-entry probability, is just over

\footnotetext{
${ }^{16}$ Data on nominal GDP, national deflators and US CPI all come from the Global Financial Database. The data on oil prices is the quarterly average of the daily West Texas oil price in USD per barrel taken from the IMF's IFS database.

${ }^{17}$ This step avoids the double counting of oil revenues and keeps the calibration consistent with the model. ${ }^{18}$ The use of a HP is fairly standard in the literature and comes with the usual caveats. See Hamilton (2018). Here we simply use the de-trended series to obtain average data moments for the size economies.

${ }^{19}$ It is worth noting that the shock processes to these series are not very persistent. Infact the half-life of these shocks can be calculated using: $h=T \log (2) / \log \left(x_{t} / x_{T}\right)$. This gives a half-life of 4.1 quarters for innovations to output and 2.2 for innovations to the oil price.
} 
2 years. This is somewhat lower than some of the evidence suggests. For example, Richmond and Dias (2009) find that countries are typically excluded for around 5.7 years following a sovereign default episode.

Table 2 below presents the full set of parameters along with their calibration value.

\begin{tabular}{|cll|}
\hline & \multicolumn{2}{|c|}{ Table 2. Calibration } \\
\hline Parameter & Value & Description \\
\hline$\rho=1 /(1+\rho)$ & .025 & Discount rate \\
\hline$\sigma$ & .976 & Discount factor \\
\hline$\xi$ & .50 & Coefficient of relative risk aversion \\
\hline$\theta$ & .25 & Inter-temporal elasticity of substitution \\
$\psi$ & .95 & Probability of re-entry into capital market \\
$\bar{s}$ & .132 & Oil revenue share \\
$r^{*}$ & .004 & Risk free interest rate \\
$\hat{r}$ & .016 & Risk premium (exogenous) \\
$r=r^{*}+\hat{r}$ & 0.02 & Real interest rate \\
\hline$\rho^{y}$ & .841 & Persistence of productivity \\
$\rho^{p}$ & .725 & Persistence of oil price \\
$\sigma_{y}$ & .015 & Std dev. of output shocks \\
$\sigma_{p}$ & .136 & Std dev. of oil price shocks \\
$\sigma^{y p}$ & .045 & Cross correlation \\
\hline
\end{tabular}

\section{B. Pricing sovereign debt}

The model described in section III introduces a link between the sovereign's ability to borrow and the cyclical properties of the commodity price. The result is that international capital markets, when setting the price of a sovereign's debt, internalize the effect that commodity price fluctuations might have on the likelihood of default.

Under certain simplifying assumption, we can derive an analytic expression for the bond price. I present a simplified Ramsey version of the model in section A of the appendix, assuming a fixed cost of default and unitary probability of re-entry following default. Using this simple model, I derive an expression for the steady-state price of sovereign debt in section A of the appendix, which I reproduce here:

$$
q=\frac{1}{R}=\frac{1-\lambda}{R\left(\delta^{\prime}(\lambda-d)-\delta+1\right)}+\frac{1}{d \delta^{\prime} R}
$$

The steady-state price of sovereign debt is a non-linear combination of the fixed cost of default, $\lambda$, the interest rate charged to the sovereign, $R$, the level of debt, $d$, the probability of the sovereign to default, $\delta$, and the sensitivity of this probability to the level of debt, $\delta^{\prime}$. When default is not possible for the sovereign we set $\delta=\delta^{\prime}=0$ and $\lambda=0$, and the bond pricing expression collapses to $q=1 / R$. This simple expression states that the steady state bond price of sovereign debt is inversely related to the interest rate facing the sovereign, $R$. 
When default is possible, this inverse relationship is augmented by the cost of default, the optimal default decision, and the level of debt. The more sensitive the default decision of the sovereign is with respect the level of debt (that is, the larger is $\delta^{\prime}$ ), the lower the price that investors are willing to pay to hold this debt, and the higher the effective interest rate. Note that the interest rate, $R$, is itself a function of the level of debt as well as the output and oil price states.

It can be seen from expression (16) that the model generates a nonlinear relationship between the bond price and commodity prices and output. Intuitively, a country is more likely to default strategically when output or commodity prices are low because, at the margin, defaulting yields higher utility than repaying the debt; rational investors would then price in such higher default probability, resulting in a positive correlation between sovereign bond yield and commodity (or output). It is worth noting that investors' beliefs about default only depends on the current level of debt and not the history of default.

Returning to the full model described in section III, I solve numerically for the optimal bond pricing schedule, which is now a complex function of the interest rate function, $R(\cdot)$, and the default decision, $\delta(\cdot)$. Figure 3 shows how the equilibrium bond price (vertical axis) varies with the level of indebtedness (horizontal axis) for different output and oil price states. The solid lines represent the schedule from Eq. 8 for 'high', 'medium' and a 'low' output states as a function of the current debt level given a 'high' oil price ${ }^{20}$. The bond price is an increasing function of foreign assets (negative assets signify a net debt position). The sovereign has a choice in any single period: (i) default on debt today, increasing consumption and so utility today, but being excluded from asset markets and facing a default cost, or (ii) do not default today, lowering consumption and utility today due to interest payments, but maintaining the ability to borrow and avoiding the negative consequences of default. When setting the bond price, international investors take the sovereign's default decision into account, decreasing the amount they would be willing to pay for this debt the more likely it is that the government will choose to default. The larger the outstanding debt (i.e. a more negative asset position), the more likely the sovereign is to default and so the lower is the bond price. The pricing schedule for the 'high' output state is above that of the 'low' output state simply because higher output realizations mean a lower chance of default. This in turn means investors are more willing to hold government debt and so are willing to pay a higher price for it. ${ }^{21}$

The dashed lines represent the same bond pricing schedules but for the 'low' oil price state. When oil prices are low the pricing schedules shift down. This is due to the oil revenue entering additively into the sovereign's budget constraint: a lower oil price reduces revenues, increasing the likelihood of default and lowering the equilibrium bond price. We get a similarly shaped bond pricing schedule in a model without oil. That is, the bond price is still a downward sloping, non-linear function of the output states. However, without oil in the model the bond pricing schedule has significantly larger steps in it.

\footnotetext{
${ }^{20}$ I use the 3rd, 6th and 9th positions for the high, medium and low states respectively.

${ }^{21}$ The model predicts default (or a zero bond price) at relatively low debt-GDP ratios (sometimes below 10 percent) in adverse oil price and output states. This may not be in line with current experience in which actual debt ratios are as high as 75 percent, without default.
} 


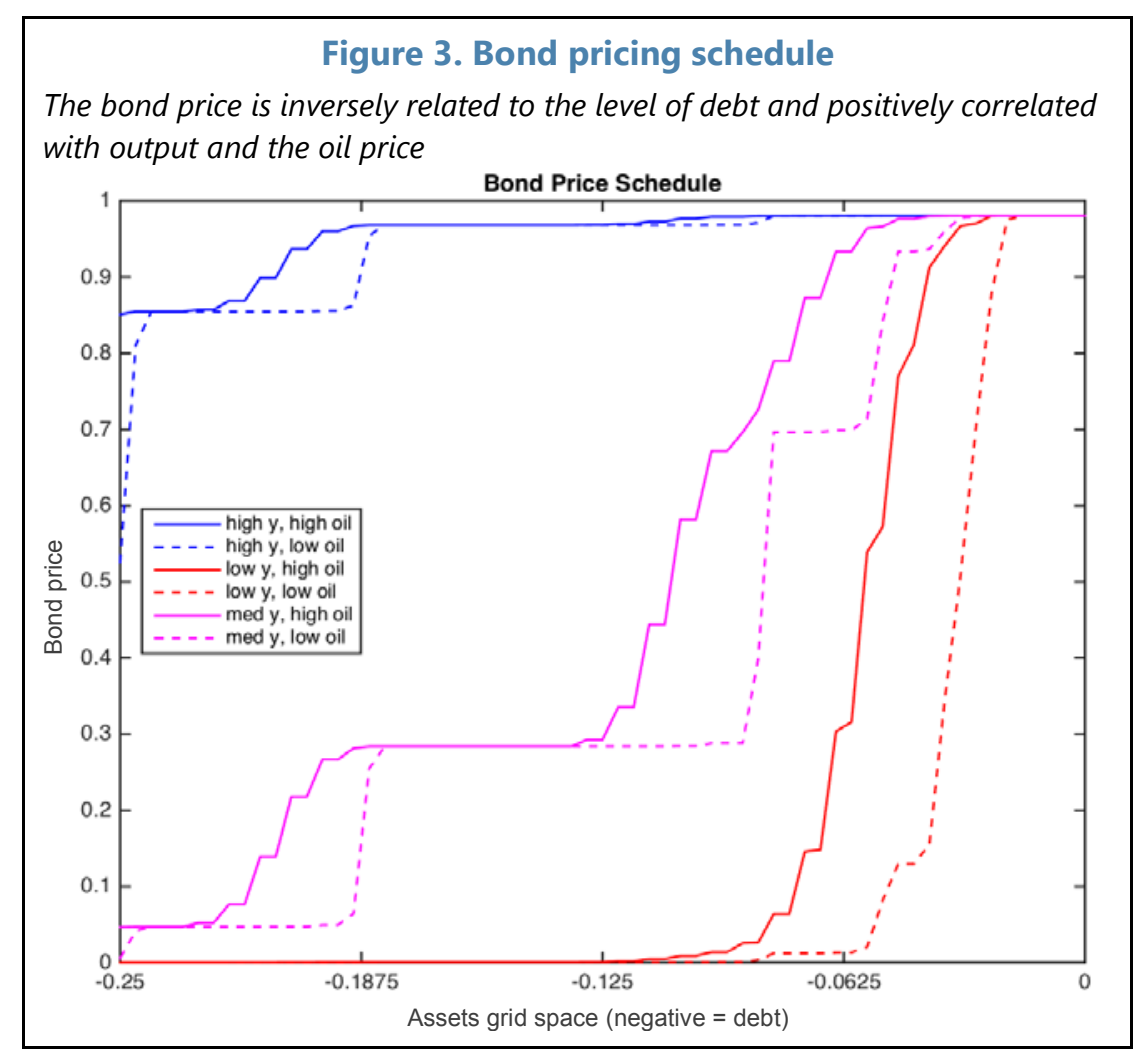

\section{Model Performance}

In this section we assess the model's ability to reproduce some of the aggregate data moments for our six resource dependent economies. ${ }^{22}$ Using the above calibration I solve the model for the sovereign's policy functions using the value function iteration algorithm. I then simulate the model over 1000 periods and compare the model moments to the data. The results are presented in tables $3 \mathrm{a}$ and $3 \mathrm{~b}$. The data covers the period $1995 \mathrm{q} 1$ to $2016 \mathrm{q} 4$ and $\mathrm{I}$ use a Hodrick-Prescott (HP) filter with a smoothing parameter of 1600 to detrended each series.

The first two columns in table 3 a present the mean AR(1) coefficients and standard deviations for output, the oil price, consumption and the interest rate spread from our panel dataset. Consumption is the most persistent series, followed by output, then the oil price and finally the interest rate spread. The oil price is the most variable. The next two columns present these same data moments from the simulated model. Overall, the model calibration fits the data relatively well, and is able to reproduce the correct ordering of autoregressive properties observed in the data. The model underpredicts the persistence and variability of

\footnotetext{
${ }^{22}$ Sovereign spreads are typically a function of many factors, both supply and demand, and estimating them using a stylized model such as that presented in this paper is bound to be challenging. The model presented here is highly stylized and ignores several important factors that likely affect the pricing of sovereign debt in these economies, including: financial market imperfections and dynamics, risk sentiment, global push factors, government failures, the composition of external vs domestic debt, the choice of fiscal and exchange rate policy, etc.
} 
the interest rate spread, by about a half, and overestimates the volatility of consumption. This is perhaps to be expected given the highly stylized nature of the model. The next two columns present these same data moments from the simulated model. The model successfully reproduces the correct signs on all of the moments, as well as the correct ordering of the persistence and standard deviation terms.

Table $3 \mathrm{~b}$ presents the cross-correlations between sovereign spreads (the key focus of the paper) and the two stochastic processes, output and the oil price. A key feature of spreads in oil-dependent, emerging market economies, is strongly countercyclical movements with oil prices. The model successfully generates this negative correlation between spreads and the oil price. Higher oil prices increase the resources available to the sovereign and reduce the likelihood of default, thus lowering sovereign spreads. This increases market access, or rather reduces the costs associated with borrowing from global financial markets. The model is also able to produce a higher correlation between spreads and the oil price than between spreads and output, which is something we observe in the data. This aspect is omitted from existing studies on sovereign default and suggests that oil price volatility is costlier than output shocks for oil-dependent EMs.

\begin{tabular}{|lcccc|}
\hline \multicolumn{3}{|c|}{ Table 3a. Model moments } \\
\hline & \multicolumn{2}{c|}{ Data } & \multicolumn{2}{c|}{ Model } \\
& AR(1) & Std. Dev. & AR(1) & Std. Dev. \\
\hline Output & 0.841 & 0.032 & 0.893 & 0.043 \\
Oil price & 0.725 & 0.198 & 0.657 & 0.195 \\
Consumption & 0.898 & 0.026 & 0.977 & 0.107 \\
Spread & 0.645 & 0.022 & 0.304 & 0.010 \\
\hline
\end{tabular}

\begin{tabular}{|lcc|}
\hline \multicolumn{3}{|c|}{ Table 3b. Model correlations } \\
\hline & Data & Model \\
\hline Output dev & -0.138 & -0.148 \\
Oil price dev & -0.279 & -0.160 \\
\hline
\end{tabular}

Despite the relative simplicity of the model described in section III, it does a relatively good job at reproducing some of the key macroeconomic fluctuations observed in the data, particularly the countercyclical behavior of the oil price and sovereign bond spread. The analysis in appendix D explores the sensitivity of the model to these parameterization choices, including: the importance of oil, covarying shocks, and deterministic preferences. It turns out that these are important elements of a model sovereign debt in oil dependent, emerging market settings. 


\section{Conclusion}

How do oil price movements affect sovereign spreads in an oil-dependent emerging market economy, and what this means for market access and pricing of sovereign debt in these settings? With debt levels across the world on the rise, this is a pertinent question for policy makers and investors alike. This paper sheds light on these two questions by investigating the link between commodity price movements and risk premiums in resource dependent emerging economies.

I present empirical evidence of a counter-cyclical relationship between oil prices and interestrate spreads in these settings. I then develop a simple model that delivers this countercyclical relationship and show that it comes relatively close to explaining some key macroeconomic co-movements in a sample of oil-rich emerging market countries. The model generates an endogenous link between oil prices and interest rate risk premiums and is, to the best of my knowledge, new to the literature. Going forward, this approach could be useful in a range of other applications involving optimal policy in resource-rich settings.

For emerging market economies, managing resource revenues typically involves some tradeoff between using revenues to raise the domestic capital stock and using them to build some form of precautionary savings to manage volatility. This paper presents further support for saving out of oil revenues: to manage volatile borrowing costs due to sovereign default risk. Large movements in the oil price present an important source of default risk for oildependent sovereigns. Policy makers could respond by building up buffers to manage downward movements in the oil price. These buffers would be larger the stronger is the link between oil prices and the domestic economy, the more impatient are policy makers, and the more willing they are to substitute current for future consumption. The continued focus on economic diversification is also important for oil-dependent economies, as it would not only reduce the co-movements of spreads with oil prices, but also increase the resilience of the economy in the face of commodity price shocks.

Finally, governments that depend significantly on oil revenues are likely to face prolonged periods of substantial interest rate premiums. This could lead to lower levels of investment and capital stocks thus hindering growth. The important role that resource revenues can play in financing domestic capital accumulation has been highlighted in recent research. Future work could extend the model developed in this paper to incorporate domestic physical capital. This would allow policymakers to answer questions about the trade-offs between precautionary savings and domestic investment under endogenous interest rate premiums. 


\section{REFERENCES}

Adam, K. and Grill, M. (2017). Optimal sovereign default. American Economics Journal: Macroeconomics, 9(1), 128-164.

Aguiar, M. and Gopinath, G. (2006). Defaultable debt, interest rates and the current account. Journal of international Economics, 69(1), 64-83.

Akay, A., Martinsson, P., Medhin, H., and Trautmann, S. T. (2012). Attitudes toward un- certainty among the poor: an experiment in rural ethiopia. Theory and Decision, 73(3), 453-464.

Arellano, C. (2008). Default risk and income fluctuations in emerging economies. The American Economic Review, 98(3), 690-712.

Arezki, R. and Bru "ckner, M. (2012). Commodity windfalls, democracy and external debt. The Economic Journal, 122(561), 848-866.

Binswanger, H. P., Barah, B., et al. (1980). Yield risk, risk aversion, and genotype selection: conceptual issues and approaches. Yield risk, risk aversion, and genotype selection: conceptual issues and approaches.

Braeu, R. (2010). Consumption tilting and the current account: Evidence from canada. International Review of Economics and Finance, 19(2), 304-312.

Caldara, D., Fernandez-Villaverde, J., Rubio-Ramirez, J.F. and Yao, W. (2012). Computing DSGE models with recursive preferences and stochastic volatility. Review of Economic Dynamics, 15(2), pp.188-206.

Cashin, P., Haque, N. U., and Olekalns, N. (2003). Tax smoothing, tax tilting and fiscal sustainability in pakistan. Economic Modelling, 20(1), 47-67.

Cashin, P. and McDermott, C. J. (2002). Intertemporal consumption smoothing and capital mobility: evidence from australia. Australian Economic Papers, 41(1), 82-98.

Chatterjee, S. and Eyigungor, B. (2012). Maturity, indebtedness, and default risk. The American Economic Review, 102(6), 2674-2699.

Collier, P. and Goderis, B. (2012). Commodity prices and growth: An empirical investigation. European Economic Review, 56(6), 1241-1260.

Deaton, A., Miller, R. I., et al. (1995). International commodity prices, macroeconomic performance, and politics in Sub-Saharan Africa. International Finance Section, Department of Economics, Princeton University.

Eaton, J. and Gersovitz, M. (1981). Debt with potential repudiation: Theoretical and empirical analysis. The Review of Economic Studies, 48(2), 289-309.

Fink, F. and Scholl, A. (2016). A quantitative model of sovereign debt, bailouts and conditionality. Journal of International Economics, 98, 176-190.

Gandelman, N. and Hernadez-Murillo, R. (2014). Risk Aversion at the Country Level, Federal Reserve Bank of St. Technical report, Louis Working Paper 5.

Grossman, H. and Van Huyck, J. (1988). Sovereign debt as a contingent claim: Excusable default, repudiation, and reputation. The American Economic Review, 78(5), 1088-1097.

Hamilton, J.D. (2018). Why you should never use the Hodrick-Prescott filter. Review of Economics and Statistics, 100(5), pp.831-843.

Harrison, M. (2010). Valuing the future: the social discount rate in cost-benefit analysis.

International Monetary Fund. Research Dept, (2017). World Economic Outlook, April 2017: Spillovers and Cycles in the Global Economy. International Monetary Fund.

International Monetary Fund. African Dept, (2018). Regional Economic Outlook, Sub-Saharan Africa, April 2018: Domestic Revenue Mobilization and Private Investment. International Monetary Fund.

Kletzer, K. M. and Wright, B. D. (2000). Sovereign debt as intertemporal barter. The American Economic Review, 90(3), 621-639.

Laibson, D. (1997). Golden eggs and hyperbolic discounting. The Quarterly Journal of Economics, 112(2), 443-478. 
Lizaro, S. (20173). Default risk and risk averse international investors. Journal of International Economoics, 89.

Lopez-Martin, B., Leal, J. and Fritscher, A.M.. (2017). Commodity price risk management and fiscal policy in a sovereign default model. Journal of International Money and Finance.

McGregor, T. (2017). Commodity price shocks, growth and structural transformation in low-income countries. The Quarterly Review of Economics and Finance, 64, 1-13.

Mehlum, H., Moene, K., and Torvik, R. (2006). Institutions and the resource curse. The economic journal, 116(508), 1-20.

Neumeyer, P. A. and Perri, F. (2005). Business cycles in emerging economies: the role of interest rates. Journal of monetary Economics, 52(2), 345-380.

Obstfeld, M. and Rogoff, K. (1995). The intertemporal approach to the current account. Handbook of international economics, 3, 1731-1799.

Ogaki, M., Ostry, J. D., and Reinhart, C. M. (1996). Saving behavior in low-and middle- income developing countries: a comparison. IMF Staff Papers, 43(1), 38-71.

Park, J. (2017). Sovereign default and capital accumulation. Journal of International Eco- nomics.

Pasten, R. and Cover, J. P. (2015). Tax tilting and politics: Some theory and evidence for latin america. Journal of Macroeconomics, 44, 208-218.

Pouzo, D. and Presno, I. (2016). Sovereign default risk and uncertainty premia. American Economic Journal: Macroeconomics, 8(3), 230-266.

Raddatz, C. (2007). Are external shocks responsible for the instability of output in low- income countries? Journal of Development Economics, 84(1), 155-187.

Ravn, M.O., Schmitt-Grohé, S. and Uribe, M. (2008). Macroeconomics of subsistence points. Macroeconomic Dynamics, 12(S1), pp.136-147.

Restrepo-Echavarria, P., Mendoza, E. and Hamann, F. (2016). Commodity Prices and Sovereign Default: A New Perspective on The Harberger-Laursen-Metzler Effect. In 2016 Meeting Papers (No. 806). Society for Economic Dynamics.

Richmond, C. and Dias, D. A. (2009). Duration of capital market exclusion: An empirical investigation.

Sachs, J. (1982). The current account in the macroeconomic adjustment process. The Scandinavian Journal of Economics, (pp. 147-159).

Sachs, J. D. and Warner, A. M. (1999). The big push, natural resource booms and growth. Journal of development economics, 59(1), 43-76.

Stähler, N. (2013). Recent developments in quantitative models of sovereign default. Journal of Economic Surveys, 27(4), pp.605-633.

Tauchen, G. (1986). Finite state markov-chain approximations to univariate and vector autoregressions. Economics letters, 20(2), 177-181.

Uribe, M. and Yue, V. Z. (2006). Country spreads and emerging countries: Who drives whom? Journal of international Economics, 69(1), 6-36.

van Binsbergen, J.H., Fernandez-Villaverde, J., Koijen, R. and Rubio-Ramirez, J. (2008). Working with epstein-zin preferences: Computation and likelihood estimation of DSGE models with recursive preferences. University of Pennsylvania.

Van der Ploeg, F. (2011). Natural resources: Curse or blessing? Journal of Economic Literature, 49(2), 366-420.

Yesuf, M. and Bluffstone, R. A. (2009). Poverty, risk aversion, and path dependence in low-income countries: Experimental evidence from ethiopia. American Journal of Agricultural Economics, 91(4), 1022-1037.

Zhuang, J., Liang, Z., Lin, T., and De Guzman, F. (2007). Theory and practice in the choice of social discount rate for cost-benefit analysis: a survey. ERD Working Paper, 94. 


\section{APPENDIX}

\section{A. Ramsey representation}

The model described in section III can be presented by the following Ramsey policy problem by setting the re-entry probability to unity:

$$
\begin{gathered}
\max _{t} \sum_{t=0}^{\infty} \beta^{t} u\left(c_{t}\right) \\
\text { s.t.: } \\
c_{t}=\omega_{t}+\frac{d_{t}}{1+R_{t}\left(y_{t}, p_{t}, \delta_{t}\right)}-\frac{f_{t}}{1+r} \\
\omega_{t}=y_{t}+p_{t} \bar{s}+f_{t-1}-d_{t-1}\left(1-\delta_{t}\left(y_{t}, p_{t}, d_{t}\right)\right)-\lambda\left(y_{t}, p_{t}\right) \delta_{t-1}\left(y_{t-1}, p_{t-1}, d_{t-1}\right) \\
d_{t} \leq 0 \text { and } f_{t} \geq 0 \\
d_{0}, y_{0}, p_{0} \text { :given }
\end{gathered}
$$

where $c_{t}$ is consumption in time $t ; \omega_{t}$ denotes wealth total wealth; $d_{t}$ is (risky) government debt; $f_{t}$ denotes safe foreign assets; $y_{t}$ is a stochastic income stream; $p_{t}$ is the stochastic oil price; and $\bar{s}$ is fixed annual oil production.

The government can save by accumulating safe foreign assets, $f_{t}$. Foreign bonds yield a riskfree return of $r$ in each period, so the price of foreign assets is given by $1 / 1+r$. The government can also issue bonds, $d_{t}$, which are issued at time $t$ and promise to pay $d_{t}$ units of consumption in period $t+1$. The government can choose to default on debt in any given period subject to some fixed cost, $\lambda\left(y_{t}, p_{t}\right)$ which is a function of the output state, $y=$ $\left\{y^{1}, \ldots, y^{n y}\right\}$, and oil price state, $p=\left\{p^{1}, \ldots, p^{n p}\right\}$, where defaulting is only for a single period with no risk of remaining excluded from international capital markets. We use $\delta_{t}\left(y_{t}, p_{t}, d_{t-1}\right) \in\{0,1\}$ to denote an indicator for default where $\delta=1$ signifies default and $\delta=0$ signifies no default. The default decision is a function of the output and oil price states as different realizations of these states will result in different optimal default decisions. It is also a function of the level of inherited debt from the last period, $d_{t-1}$. This is important for two reasons. The higher is indebtedness the more incentive the government has to default and so avoid repayment, but this default cost is a function of output and the oil price. Finally, we impose that $\delta=0$ if $d_{t-1} \leq 0$. That is, the government cannot default if it has positive assets (or negative debt).

The interest rate on government debt is given by $R_{t}$ and depends on the default profile, $\delta_{t}$, chosen by the government and on the current output and oil price states, $y_{t}$ and $p_{t}$, as these will affect the likelihood of entering different states in $t+1$. The government takes into account in its optimisation problem the effect that future default decisions have on the bond price today which is defined by the function $R_{t}($.$) .$

Setting up the Lagrangian and differentiating yields the following six FOCS, where $\xi$ is the Lagrange multiplier: 


$$
\begin{aligned}
& c_{t}: u^{\prime}\left(c_{t}\right)-\xi_{t}=0 \\
& f_{t}:-\frac{\xi_{t}}{1+r}+\beta \xi_{t+1}=0 \\
& d_{t}: \xi_{t}\left[\frac{-d_{t} \delta_{t}^{\prime} R_{t}+R_{t}+1}{\left(1+R_{t}\right)^{2}}\right]-\beta \xi_{t+1}\left(\delta_{t}^{\prime}\left(\lambda-d_{t}\right)-\delta_{t}+1\right)=0 \\
& \delta_{t}:-\xi_{t}\left[\frac{d_{t} R_{t}^{\prime}}{\left(1+R_{t}\right)^{2}}\right]+\beta \xi_{t+1}(1-\lambda)=0
\end{aligned}
$$

Combining these FOCs with the budget constraint yields the consumption Euler equation, and equation for optimal debt, and the default Euler equation as follows:

$$
\begin{gathered}
\frac{u^{\prime}\left(c_{t}\right)}{u^{\prime}\left(c_{t+1}\right)}=\beta(1+r) \\
\frac{1+r}{1+R_{t}}\left[\frac{-d_{t} \delta_{t}^{\prime} R_{t}+R_{t}+1}{1+R_{t}}\right]=\left(\delta_{t}^{\prime}\left(\lambda-d_{t}\right)-\delta_{t}+1\right) \\
\frac{1+r}{1+R_{t}}\left[\frac{d_{t} R_{t}^{\prime}}{1+R_{t}}\right]=(1-\lambda)
\end{gathered}
$$

Solving these conditions in the steady state, substituting in for the bond price, $q=1 / R$, and rearranging gives the bond pricing schedule in this simple Ramsey model:

$$
q=\frac{1}{R}=\frac{1-\lambda}{R\left(\delta^{\prime}(\lambda-d)-\delta+1\right)}+\frac{1}{d \delta^{\prime} R}
$$

When default is not possible for the sovereign, $\delta=\delta^{\prime}=0$ and $\lambda=0$, so the bond pricing expression collapses to, $q=1 / d R$. This simple expression states that the steady state bond price of sovereign debt is inversely related to the level of debt, $d$, and the interest rate facing the sovereign, $R$. When default is possible, this inverse relationship is augmented by the cost of default, $\lambda$, and the marginal effect of the level of debt on the optimal default decision by the sovereign, $\delta^{\prime}$. The more sensitive the default decision of the sovereign is with respect the level of debt (that is, the larger is $\delta^{\prime}$ ), the lower the price investors are willing to pay to holding this debt (and the higher the effective interest rate).

\section{B. Bivariate Markov shocks}

We follow Tauchen (1986) in the exposition of a discretized state-space representation of a Markov shock process. Instead of using a single variable process however, we assume a bivariate auto-regressive shock process consisting of two correlated variables, $x_{t}$ and $y_{t}$. Consider the following shock process in matrix form:

$$
\begin{gathered}
{\left[\begin{array}{l}
x_{t} \\
y_{t}
\end{array}\right]=\left[\begin{array}{cc}
\rho_{x} & \rho_{x y} \\
\rho_{y x} & \rho_{y}
\end{array}\right]\left[\begin{array}{l}
x_{t-1} \\
y_{t-1}
\end{array}\right]+\left[\begin{array}{l}
\varepsilon_{x, t} \\
\varepsilon_{y, t}
\end{array}\right]} \\
\boldsymbol{z}_{t}=\boldsymbol{\rho} \mathbf{z}_{t-1}+\boldsymbol{\varepsilon}_{t}
\end{gathered}
$$


where $\boldsymbol{\varepsilon}_{t} \sim N(\boldsymbol{\mu}, \boldsymbol{\Sigma}), \boldsymbol{\mu}=\left[\begin{array}{l}0 \\ 0\end{array}\right]$ and $\boldsymbol{\Sigma}=\mathrm{E}\left(\boldsymbol{\varepsilon} \boldsymbol{\varepsilon}^{\prime}\right)=\left[\begin{array}{cc}\sigma_{x} & \sigma_{x y} \\ \sigma_{y x} & \sigma_{y}\end{array}\right]$. Then we can express the expected value of $\boldsymbol{z}_{t}$ and its variance as:

$$
\begin{gathered}
\mathrm{E}\left(\mathbf{z}_{t}\right)=0 \\
\operatorname{Var}\left(\mathbf{z}_{t}\right)=\mathbf{\Omega}=\left[\begin{array}{cc}
\omega_{x} & \omega_{x y} \\
\omega_{y x} & \omega_{y}
\end{array}\right]=\boldsymbol{\Sigma}[\mathbf{I}-\boldsymbol{\rho}]^{-1}
\end{gathered}
$$

We define a state space grid for the correlated variables as:

$$
\left[\begin{array}{l}
x_{1} \\
y_{1}
\end{array}\right]<\left[\begin{array}{l}
x_{2} \\
y_{2}
\end{array}\right]<\cdots<\left[\begin{array}{l}
x_{m} \\
y_{n}
\end{array}\right]
$$

where

$$
\begin{gathered}
\boldsymbol{z}_{1}=\left[\begin{array}{l}
x_{1} \\
y_{1}
\end{array}\right]=\left[\begin{array}{l}
-r \omega_{x} \\
-r \omega_{y}
\end{array}\right] \\
\boldsymbol{z}_{m n}=\left[\begin{array}{l}
x_{m} \\
y_{n}
\end{array}\right]=\left[\begin{array}{l}
r \omega_{x} \\
r \omega_{y}
\end{array}\right] \\
\boldsymbol{d}=\left[\begin{array}{l}
d_{x} \\
d_{y}
\end{array}\right]=\left[\begin{array}{c}
x_{i}-x_{i-1} \\
y_{k}-y_{k-1}
\end{array}\right]
\end{gathered}
$$

and $r$ is the state-space factor, which we set to 3. Since $\operatorname{Pr}\left(\boldsymbol{\varepsilon}_{t} \leq \boldsymbol{u}\right)=F\left([\boldsymbol{u}-0] \boldsymbol{\Sigma}^{-1}\right)$, we can define the transition probability matrix, $\boldsymbol{\Pi}_{i j, k l}$, as:

$$
\begin{gathered}
\boldsymbol{\Pi}_{i j, k l}=\operatorname{Pr}\left\{\boldsymbol{z}_{j l}-\boldsymbol{d} \backslash 2 \leq \boldsymbol{\rho} \boldsymbol{z}_{i k}+\boldsymbol{\varepsilon}_{t} \leq \boldsymbol{z}_{j l}+\boldsymbol{d} \backslash 2\right\} \\
=\mathrm{F}\left(\left[\boldsymbol{z}_{j l}-\boldsymbol{\rho} \boldsymbol{z}_{i k}+\boldsymbol{d} \backslash 2\right] \boldsymbol{\Sigma}^{-1}\right)-\mathrm{F}\left(\left[\boldsymbol{z}_{j l}-\boldsymbol{\rho} \boldsymbol{z}_{i k}-\boldsymbol{d} \backslash 2\right] \boldsymbol{\Sigma}^{-1}\right)
\end{gathered}
$$

where $\boldsymbol{\Pi}$ is a matrix of dimension $(m \times n \times m \times n)$, and $\mathrm{F}($.$) denotes the CDF of a bivariate$ normal distribution, subscript $i j$ denotes the probability of moving from the $i$ th position to the $j$ th position of variable $x$ and $k l$ denotes the probability of moving from the $k$ th position to the $l$ th position of variable $y$. The boundary transition probabilities are given by:

$$
\boldsymbol{\Pi}_{i 1, k 1}=\mathrm{F}\left(\left[\boldsymbol{z}_{11}-\boldsymbol{\rho} \mathbf{z}_{i k}+\boldsymbol{d} \backslash 2\right] \boldsymbol{\Sigma}^{-1}\right)
$$

and

$$
\boldsymbol{\Pi}_{i m, k n}=\mathrm{F}\left(\left[\mathbf{z}_{m n}-\boldsymbol{\rho} \mathbf{z}_{i k}-\boldsymbol{d} \backslash 2\right] \boldsymbol{\Sigma}^{-1}\right)
$$

I have developed Matlab code that estimates the transition matrix for a bivariate VAR process as described here, and another that simulates a Markov chain using this bivariate transition matrix. These codes allow the user to set the deep parameters of the bivariate process as well as the state space for the model. ${ }^{23}$.

${ }^{23}$ Please visit https://thomasmjmcgregor.wordpress.com/data/ 


\section{Solving the model}

The above equations fully characterize a simple model of sovereign default in resource-rich, emerging market settings. Due to the non-linear nature of the model, it is necessary to use numerical methods to solve for the optimal policy functions. Here I use a value-function iteration approach. This is implemented by discretizing the state-space for debt, output and oil revenues ${ }^{24}$, using a Markov chain for the stochastic output and oil price processes, and solving for the policy functions using a guess and verify procedure.

The recursive solution to the model consists of a set of policy functions for the representative agents' choice of consumption, $c\left(d_{t}, y_{t}, p_{t}\right)$, as well as default decision, $(D, N)$, and optimal asset holdings in the following period, $d_{t+1}$; and a bond pricing function, $q\left(d_{t+1}, y_{t}, p_{t}\right)$, which reflects the sovereign's default probabilities and is consistent with the creditors' expected zero profit condition. For a given choice of parameters, the numerical solution method involves: taking an initial guess for the bond price schedule and the value functions, under default and no-default, and solving for the optimal policy functions and probability of default. The bond pricing schedule is then updated using the probability of default and the preceding steps repeated until the problem converges.

A simplified RBC version of the model in section III is presented in this appendix in which I derive expressions for several analytical properties of the model. I show that the Euler equation of the RBC debt model collapses to that of a standard real business cycle (RBC) model when default is not an option for the sovereign. Further, I show that there is a single parameterization of the fixed default cost and risk-free interest rate such that the optimal debt choice collapses to that of a simple RBC model with perfect capital markets.

The optimal choice of sovereign debt depends crucially on whether we allow for default. Without default the level of debt is decreasing in the elasticity of the sovereign's interest rate with respect to the level of indebtedness. That is, the more the interest rate charged on borrowing, or conversely the bond price, responds to the level of outstanding debt, the less the sovereign chooses to borrow.

\section{Solution algorithm}

The numerical solution method involves the following steps:

1. Choose parameters values for: $\left\{\rho, \theta, \sigma, \xi, \psi, \bar{s}, r, \rho^{y}, \rho^{p}, \rho^{y p}, \sigma_{y}, \sigma_{p}\right\}$

2. Discretize the state spaces for $y, d$, and $p$. I use 11 output and oil price states, 125 debt states.

3. Start with a guess of the bond price schedule $q^{0}(d, y, p)=1 / 1+r$ and use this to solve the sovereign's problem using value function iteration, obtaining the optimal policy functions for consumption, asset holdings and default choice.

4. Given these policy functions, compute the probability of default, $\delta\left(d^{\prime}, y, p\right)$.

\footnotetext{
${ }^{24}$ I use 11 output states, 11 oil price states and 125 debt states.
} 
5. Update the bond pricing schedule given this probability of default and use this updated schedule to repeat steps 3-4 until the convergence criterion has been reached, namely $q^{0}(d, y, p)-q^{1}(d, y, p)<\Delta$, where $\Delta$ is a small number.

\section{Sensitivity}

In this section I test the sensitivity of the model to some key parameter calibrations.

\section{Oil dependence and impatience}

I vary the rate of time preference in the model in the range, $\rho=[0.01,0.05]$, per quarter, which works out at a discount rate roughly in the range of $4-20 \%$ per annum. I also vary the oil share parameter in the range, $\bar{s}=[0.02,0.6] .{ }^{25}$

Figure A1a presents the AR(1) parameter for the interest rate spread for different combinations of impatience and oil dependence, while figure A1b presents the spread's correlation with the oil price for the same combinations ${ }^{26}$ The non-linear relationship between these deep parameters and the data moments is again clear. Broadly speaking, a higher level of impatience reduces the persistence of the interest rate spread whilst a higher oil share increases it. The more impatient the sovereign is, the more they tilt consumption to the present and push debt repayments to the future. This in turn increases the probability of default, ceteris paribus, thus increasing the interest rate spread. The more important oil revenues are to the sovereign, the more likely oil price shocks are to have an impact on the ability to meet debt repayments, and in turn on the likelihood of default.

The correlation between the spread and the oil price is given in figure A1b. There is a relatively strong positive relationship between increasing impatience and oil dependency and the strength of the negative correlation between interest rate spreads and movements in the oil price. Impatience and oil dependency have a similar effect here. They both act to bring consumption forward and push debt repayments back, thus increasing the default probability when oil prices (and output) are low and raising risk premiums.

\footnotetext{
${ }^{25}$ Given the computational weight of solving and simulating the model for different parameter sets jointly, I choose 5 evenly spaced points covering each parameter range.

${ }^{26}$ Given the discretised state-space and the numerical solution method, the data moments estimated from the simulations display significant estimation noise. I therefore display a smoothed version of these estimates in the figures.
} 


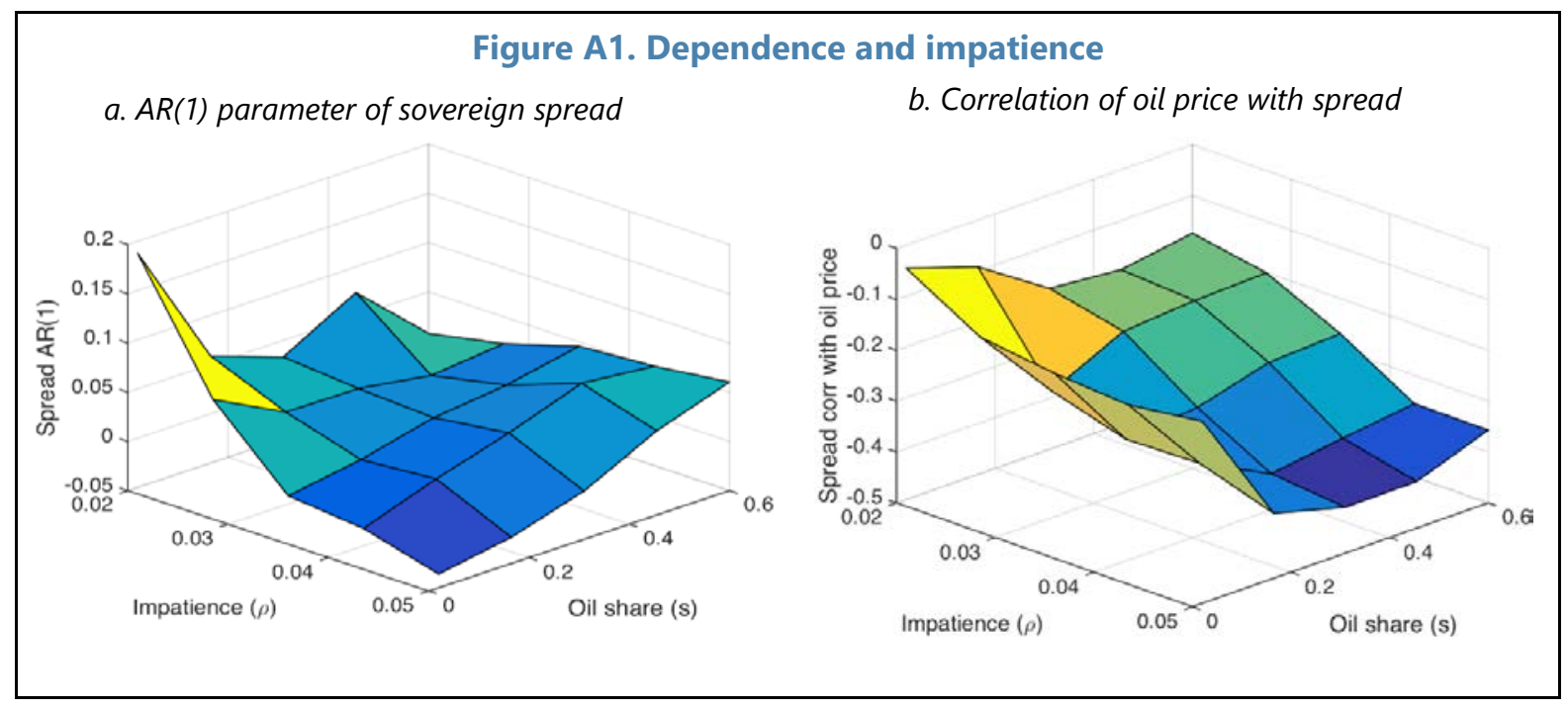

Finally, I solve and simulating the model with oil revenues turned off completely. The result is a substantial worsening in the model's predictive power. In particular the spread persistence and the countercyclical correlation of the spread and the oil price are dramatically reduced. The following two tables compare the moments of the simulated data from the model with oil to the data moments for our six resource rich economies between $1995 \mathrm{q} 1$ and $2016 \mathrm{q} 3$.

\begin{tabular}{|lcccc|}
\hline \multicolumn{3}{|c|}{ Table A1a. Model moments } \\
& \multicolumn{2}{c|}{ Data } & \multicolumn{2}{c|}{ Model } \\
& AR(1) & Std. Dev. & AR(1) & Std. Dev. \\
\hline Output & 0.841 & 0.032 & 0.829 & 0.043 \\
Oil price & 0.725 & 0.198 & 0.656 & 0.195 \\
Consumption & 0.898 & 0.026 & 0.923 & 0.035 \\
Spread & 0.645 & 0.022 & 0.001 & 0.005 \\
\hline
\end{tabular}

\begin{tabular}{|lcc|}
\hline \multicolumn{3}{|c|}{ Table A1b. Model correlations } \\
\hline & Data & Model \\
\hline Output dev & -0.138 & -0.125 \\
Oil price dev & -0.279 & -0.090 \\
\hline
\end{tabular}

\section{Covarying shocks}

The importance of covarying oil price and output shocks in the model can be explored by varying the strength of this correlation, particularly given a lack of tight priors. I explore the dynamics of the model for a reasonable range of values around the central estimate of $\rho^{y p}=$ $0.045 .{ }^{27}$ I choose upper and lower values for the covariance parameter of 0.01 and 0.10 respectively and solve the model for 50 points in between these bounds. In each case, the model is then simulated over 1000 periods and the various data moments retrieved. I focus on

\footnotetext{
27 The cross-correlation in the four countries in our sample ranges from -0.007 to +.077 .
} 
the estimates of the spread persistence and the its correlation with the oil price from the simulated data, as these are the key data moments we are trying to explain.

Once again, figures A2a and A2b present the spread persistence and the spread's correlation with oil prices respectively for different combinations of risk aversion and inter-temporal substitutability. The auto-regressive properties of the interest rate spread are reduced for very low and very high correlations of output and oil price shocks. For high and low correlations, the model displays a low spread auto-correlation, whilst for moderate correlations the spread is relatively persistent. The reason for this inverse-u shape is that there are two competing effects influencing interest rate spreads as the two shocks become more correlated. The first is an increased risk of default which drives up spreads. When the shocks are independent they act as partial insurance mechanisms against each other, and so default is less likely, ceteris paribus, and spreads remain low. As the shocks become more correlated, periods of low output combined with low oil prices become more frequent, thus increasing the likelihood of default and raising the risk premium. The second effect is the rising cost associated with default as default becomes more frequent. As the shocks become more correlated and the risk of default increases, the sovereign finds a lower level of indebtedness optimal at a given point in time. This in turn reduces the likelihood of default and so too the spread persistence.

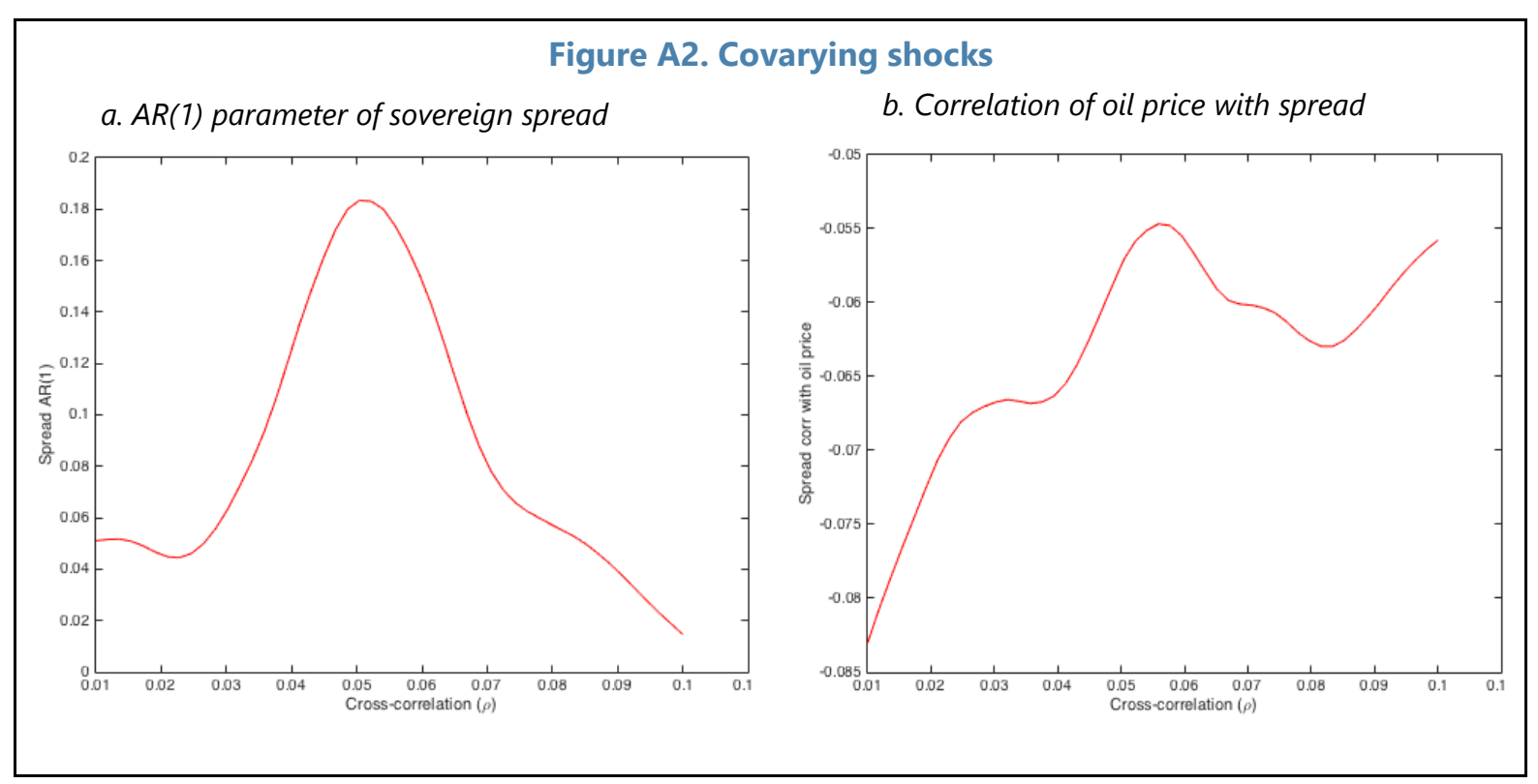

\section{Preferences}

The use of recursive preferences allows us to move the IES independently from the riskaversion parameter. Exactly what values to choose for these parameters however, is unclear. The micro and macroeconomic evidence suggests a range of possible values for these parameters in developing and emerging market settings. I solve and simulate the model, as before, using a range of plausible values for the risk-aversion and inter-temporal substitution parameters, $\sigma \in[2,100]$ and $\xi \in[0.1,0.5]$. 
Once again, figures $\mathrm{A} 3 \mathrm{a}$ and $\mathrm{A} 3 \mathrm{~b}$ present the spread persistence and the spread's correlation with oil prices respectively for different combinations of risk aversion and inter-temporal substitutability. The persistence of the interest rate spread remains relatively unaffected by changes in either parameter. However, the same is not true for the correlation of the spread with the oil price. The easier it is for the sovereign to substitute consumption inter-temporally (that is a higher IES coefficient), the greater is the negative correlation between spreads and movements in the oil price. This is due to the trade-off between consumption and debt stability. The easier it is for the sovereign to substitute consumption between periods, the more volatile consumption will be. At the same time, the path for debt will be more stable. However, this immediately means that when the oil price rises again, the level of outstanding debt will be reduced relatively slowly, thus increasing the risk of default, ceteris paribus. International creditors know this, and so charge a higher risk premium when oil prices fall initially. A similar, albeit less pronounced, relationship exists with the risk aversion parameter.

Figure A3. Preferences

a. $A R(1)$ parameter of sovereign spread

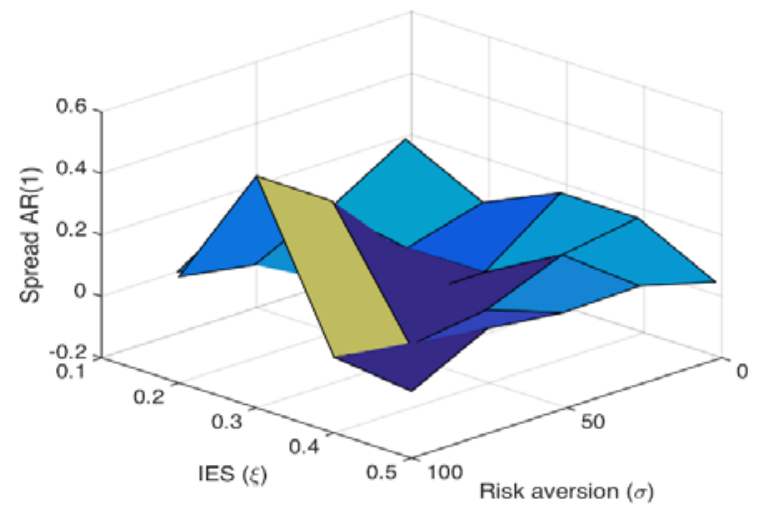

b. Correlation of oil price with spread

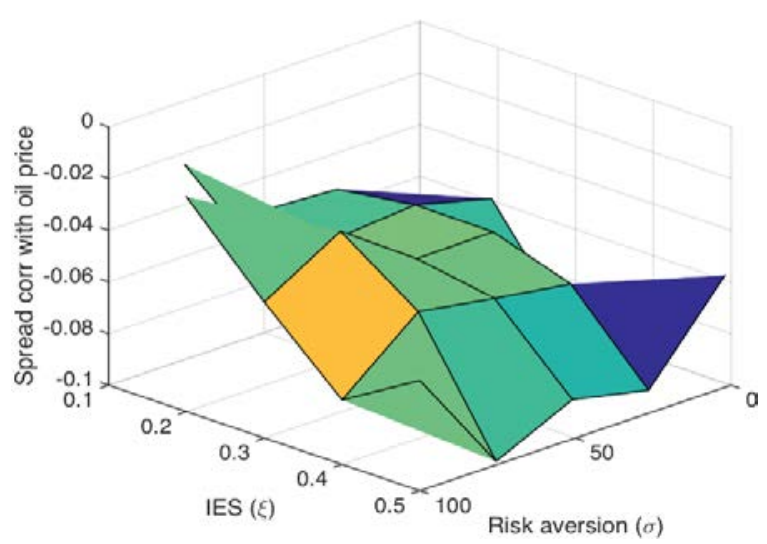

